\title{
CHROMATIN STRUCTURE OF HORMONO-DEPENDENT PROMOTERS
}

\author{
Jacques Adom, Kimberly D. CarR, Fabrice GouilleuX, Véronique MarSaUd and \\ HÉlÈnE RichaRD-FOY* \\ Unité de Recherches sur les Communications Hormonales, INSERM U-33, Hôpital du Kremlin Bicêtre, \\ 78 Avenue du Général Leclerc, 94275 Bicêtre Cedex, France
}

\begin{abstract}
Summary-Transient transfections of mutated MMTV LTRs, driving the luciferase reporter gene, have shown the presence of at least one cis-acting element cooperating with the GREs. Studies of the chromatin structure of two glucocorticoid-regulated promoters, the mouse mammary tumor virus (MMTV) long terminal repeat (LTR), a retroviral promoter, and the rat tyrosine aminotransferase (TAT) promoter, demonstrate that both DNAs are organized into precisely positioned nucleosomes. Hormonal activation of transcription is accompanied by structural changes of one (MMTV LTR) or two (TAT promoter) nucleosomes associated with the hormone-response elements (HREs). These changes can be visualized by the appearance of DNasel hypersensitive sites. Association of the hormone-receptor complex with the nucleus is necessary to induce the DNasel hypersensitive site and to maintain transcription, but is not necessary to maintain DNasel hypersensitivity. Anti-hormones, even when able to promote a strong binding of the receptor to the nucleus, are unable to induce the chromatin structural change. Using cell lines containing approx. 200 copies of a MMTV LTR $/{ }^{\mathrm{H}} \mathrm{V}$-ras chimeric construct, we have demonstrated a strong, hormono-independent nuclear matrix interaction of sequences located just upstream and downstream of the ras coding sequences.
\end{abstract}

\section{INTRODUCTION}

Gene regulation by steroid hormones is a multistep process involving interaction of the "activated" hormone-receptor complexes with their cognate target DNA sequences, termed HREs (hormone-responsive elements) [1,2]. HREs are generally found in the $5^{\prime}$ flanking DNA sequences, and can be at large distances upstream from the CAP site. In the absence of hormone, HREs can be intimately associated with histones. This chromatin organization may considerably limit sequence accessibility to diffusible regulatory proteins, particularly if nucleosomes occupy precise positions relative to the DNA sequence. Precisely positioned nucleosomes have been demonstrated on a variety of putative gene regulatory regions (for reviews see Refs [3-5]), although their role in transcription control is still poorly understood. In yeast, conditional mutations of histone $\mathrm{H} 4$ lead to an overall destabilization of chromatin structure and result in the transcriptional activation of $\sim 1 / 3$ of the genome [6]. Concomitantly with gene activation, the chromatin structure of regu-

Proceedings of the VIIIth International Congress on Hormonal Steroids, The Hague, The Netherlands, 16-21 September 1990.

*To whom correspondence should be addressed. latory regions is often disrupted, generating nucleosome-free stretches of DNA. These nucleosome-free regions can be detected by their hypersensitivity to DNasel $[5,7]$.

In most instances, this chromatin disruption takes place during DNA replication, probably as a result of the binding of one or several newly synthesized regulatory protein(s) to specific sequences, preventing nucleosome assembly on the new DNA [8]. These DNasel hypersensitive sites, once established at a given differentiation stage of the cell, persist through replication until the cell is further differentiated. For steroidregulated genes, the situation is different, since hormono-dependent DNasel hypersensitive sites, located over HREs, can be visualized shortly after hormonal treatment $[9,10]$. This excludes a role for replication in their establishment. In addition, these hypersensitive sites are only present when hormone is present and disappear shortly after its withdrawal.

Our group focuses on understanding the role of chromatin structure in the modulation of transcription levels of steroid-regulated genes. We are currently investigating two glucocorticoid regulated promoters: MMTV LTR (mouse mammary tumor virus long terminal repeat), a retroviral promoter; and rat TAT (tyrosine aminotransferase), a eukaryotic promoter. 
The hormono-dependent MMTV LTR has been extensively studied by several laboratories. It is a complex promoter under glucocorticoid, progestin, androgen, and mineralocorticoid regulation that also displays, in vivo, a mammary tissue-specific expression. Both primary DNA sequence and conformation (chromatin-structure) are involved in a set of positive and negative regulatory events. The chromatin organization of the MMTV LTR has previously been described [11]. The presence of an array of precisely positioned nucleosomes on all of the LTR was demonstrated in the absence of hormone, when there is no transcription. Hormonal treatment of the cells triggers transcription. At the same time, a local change of the chromatin structure over the DNA sequences (GREs) interacting with the hormone-receptor complex can be demonstrated by the appearance of a DNasel hypersensitive site and MPE-Fe(II) cleavage of this region which is uncut in the absence of hormone [9-11]. It has also been demonstrated by in vivo exonuclease III footprinting that the association of transcription factor NF-I with its target on the MMTV promoter requires the presence of hormone [12] and is prevented by the presence of antagonists [13]. In vitro reconstitution studies have shown that it is possible to reassemble a nucleosome over the region containing the $\operatorname{GRE}[14,15]$. The glucocorticoid receptor is able to interact with its target sequences packaged in a nucleosome structure $[14,15]$, but NF-I is not [15]. These observations suggest that, in the absence of hormone, the NF-1 recognition site is sequestered in the chromatin structure and that upon hormone-receptor complex interaction with the GRE a nucleosome is displaced, thus freeing the NF-I target sequence.

The roles of various regions of the LTR in the control of transcription levels have been studied by transient transfection assays and in transgenic mice [16-19]. In transgenic mice the distal part of the MMTV LTR seems to be important for mammary tissue-specific expression [19]. Transi- ent transfection studies have identified two regions as putative targets for negative regulatory factors $[17,18]$. However, it is not known if such elements are functional when the DNA is wrapped into nucleosomes.

The rat tyrosine aminotransferase promoter is under the control of multiple regulatory events: it is stimulated by glucocorticoids and cAMP, and the gene is expressed in a tissue-specific manner. The $5^{\prime}$ flanking sequences have been independently cloned by two groups [20,21], and the sequence of $10 \mathrm{~kb}$ of $5^{\prime}$ flanking sequences has been published [22]. Elements involved in glucocorticoid transcriptional activation have been identified by transient transfection experiments $[21,23,24]$. DNasel hypersensitivity in the presence and absence of hormone has been investigated over a $20 \mathrm{~kb}$ region [23-25]. There is only one region displaying a hormono-dependent hypersensitivity to DNasel, located at approx. $-2.5 \mathrm{~kb}$ of the CAP site. It contains three GREs: one is only a half palindrome and the other two are classical partially degenerated palindromes.

\section{CIS-ELEMENTS MODULATING THE LEVEL OF TRANSCRIPTION OF MMTV LTR}

MMTV is the major etiologic agent in mouse mammary adenocarcinomas. In rare cases, it is associated with lymphomas in mice. In this situation, the newly acquired MMTV proviruses always undergo a rearrangement, with a large deletion of $\sim 400 \mathrm{bp}$ in the LTR, just upstream of the GREs. We have constructed plasmids containing the MMTV LTR deleted in this region, driving the luciferase reporter gene. The basal and dexamethasone-induced luciferase levels were measured after transient transfection into two cell lines: NIH 3T3 (immortalized mouse fibroblasts) and 34i (transformed mouse mammary epithelial cells). Table 1 summarizes the most striking results. It can be noted that in $34 \mathrm{i}$ cells the full-length MMTV promoter

Table 1. Transient transfections of MMTV LTR constructions

\begin{tabular}{|c|c|c|c|c|c|c|}
\hline Cell line & \multicolumn{2}{|c|}{$34 \mathrm{i}$} & \multicolumn{2}{|c|}{ NIH-3T3 } & \multicolumn{2}{|c|}{ NIH-3T3 } \\
\hline Receptor cotransfected & \multicolumn{2}{|c|}{-} & \multicolumn{2}{|c|}{-} & \multicolumn{2}{|c|}{+} \\
\hline Dexamethasone & - & + & - & + & - & + \\
\hline pFC311uc & 18.4 & 388.9 & 10.1 & 46.6 & 18.8 & 1289.0 \\
\hline pC3DSAluc & 18.2 & 131.5 & 9.9 & 9.6 & 22.8 & 262.3 \\
\hline pSVDS'luc & 607.3 & - & 631.5 & - & - & - \\
\hline
\end{tabular}

Cell lines $34 \mathrm{i}\left(10^{6}\right.$ cells/plate) and NIH-3T3 $\left(5.10^{7}\right.$ cells/plate) were transiently transfected with $5 \mu \mathrm{g}$ of plasmid pFC31luc (full length LTR), pC3DSAluc (LTR deleted from -636 to -201 ) or pSVD5'luc (control plasmid containing the SV40 promoter driving the luciferase gene), along with $5 \mu \mathrm{g}$ of plasmid pCH110 (SV40 promoter driving the $\beta$-galactosidase gene) and, when indicated, $5 \mu \mathrm{g}$ of a plasmid expressing the glucocorticoid receptor. In the table are presented the mean values of 3 independent transfections, corrected for differences in transfection efficiencies (using the cotransfected control plasmid pCH110) and expressed in arbitrary units. 
(pFC31luc) is very active in the presence of hormone (induction $\sim 22$-fold). In contrast, it is very weak in NIH-3T3 cells (induction $\sim 4.5$ fold). Increasing the glucocorticoid receptor content of NIH-3T3 cells, by cotransfection of the receptor gene, results in a considerable increase in the MMTV promoter activity, becoming more efficient than in $34 \mathrm{i}$ cells (induction $\sim 68$-fold). The deletion of a region outside the GREs, spanning from -636 to -201 (pC3DSAluc), leads to a noticeable decrease in the intensity of hormonal response. The most spectacular effect is obtained in NIH-3T3 cells, in which the deletion of this region abolishes the hormonal response. In 34i cells and NIH-3T3 cells (in which the glucocorticoid receptor has been transfected) the effect of the mutation results in a decrease in induced luciferase activity of 66 and $80 \%$, respectively. These results suggest a cooperation between this region and the GREs. The cooperation may be more efficient in NIH-3T3 cells than in 34i cells and increased when there is a relatively low content in glucocorticoid receptor $(50 / 100 \mathrm{pmol} / \mathrm{mg}$ cytosol protein).

\section{CHROMATIN STRUCTURE OF HORMONO-DEPENDENT PROMOTERS}

\section{$M M T V L T R$}

We have investigated the chromatin structure of the MMTV LTR in cell lines in which were established chimeric constructs containing the LTR, driving a reporter gene, and $69 \%$ of the bovine papilloma virus genome (BPV), as a eukaryotic vector. These cell lines contain $\sim 200$ copies/cell of the construct [26]. We have digested nuclei from 1361.5 cells (in which the reporter gene is ${ }^{\mathrm{H}} \mathrm{v}$-ras), treated or not with dexamethasone, with increasing amounts of micrococcal nuclease. Figure 1, left panel, shows the nucleosome ladder resulting from the digestion of cellular DNA. The right panel shows the pattern obtained after transfer of the DNA onto a membrane and hybridization with a LTR probe. These data allow us to conclude that MMTV LTR DNA from the chimeric constructs is wrapped in nucleosomes, whether the hormone is present or not. Studies on nucleosome positioning over the LTR were performed using two methods for probing linker region positions: micrococcal nuclease digestion and MPE-Fe(II) cleavage [11]. Figure 2 presents the result of an experiment in which nuclei from

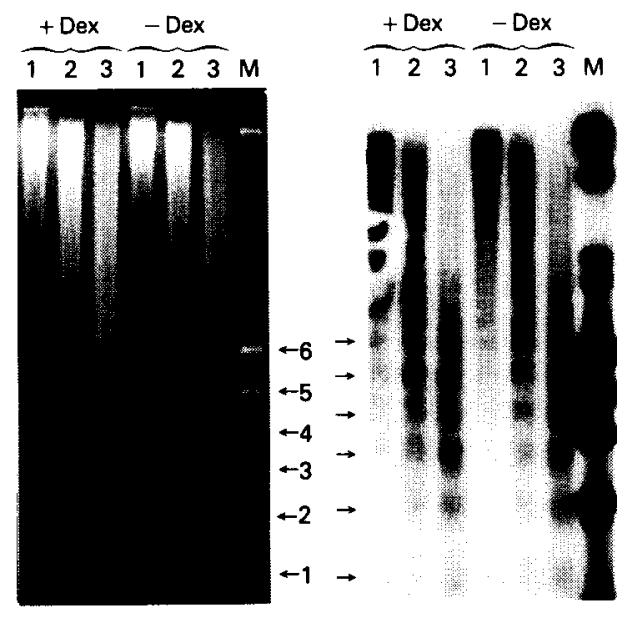

Gel: UV

Blot: LTR PROBE

Fig. 1. Chromatin structure of MMTV LTR. Nuclei from 1361.5 cells (treated or not with $50 \mu \mathrm{M}$ dexamethasone) were resuspended at an $O D_{260}=40$ and digested with increasing amounts of micrococcal nuclease for $5 \mathrm{~min}$. at $25^{\circ} \mathrm{C}$ (lanes 1-3: 30, 60 and $120 \mathrm{U} / \mathrm{ml}$ of nuclear suspension). After purification, the DNAs were cleaved with Eco RI to decrease their viscosity, and $10 \mu \mathrm{g}$ were loaded in each lane of a $2 \%$ agarose gel. The left panel shows the total DNA profile and the right shows size distribution of MMTV LTR DNA sequences. The arrows with numbers indicate the position of mono(1), di (2), and polynucleosomes(3-6). $\mathrm{M}$ : marker lane.

cells treated for $2 \mathrm{~h}$ with increasing concentrations of dexamethasone were cleaved with MPE-Fe(II). After purification the DNAs were digested to completion with Ava I or Pst I, were fractionated on agarose gels, transferred to membranes, and hybridized with probes P4-A (top panel) and ${ }^{\mathrm{H}} \mathrm{v}$-ras (bottom panel). Lanes $\mathrm{C}$ of the two blots show clear bands, demonstrating precise nucleosome positioning on the LTR in the absence of hormone (lanes 0 ). Treatment with increasing concentrations of dexamethasone induces a change in the cutting pattern, with an increase in the intensity and width of the band located around -150 to -200 in both blots. These results agree with the dosedependent, hormono-induced establishment of a DNasel hypersensitive site centered around position -165 of the LTR [11].

Anti-hormones are unable to induce the conformational change of the nucleosome. In the cell line 904.13 (which contains 200 copies of the chimeric construct described above, with ${ }^{\mathrm{H}} \mathrm{v}$-ras as a reporter gene), dexamethasone-mesylate is a pure antagonist, also able to induce nuclear transfer of the glucocorticoid receptor [27]. We have investigated the effect of this anti-hormone on DNasel hypersensitivity in this cell line. The antagonist, under conditions in which the 

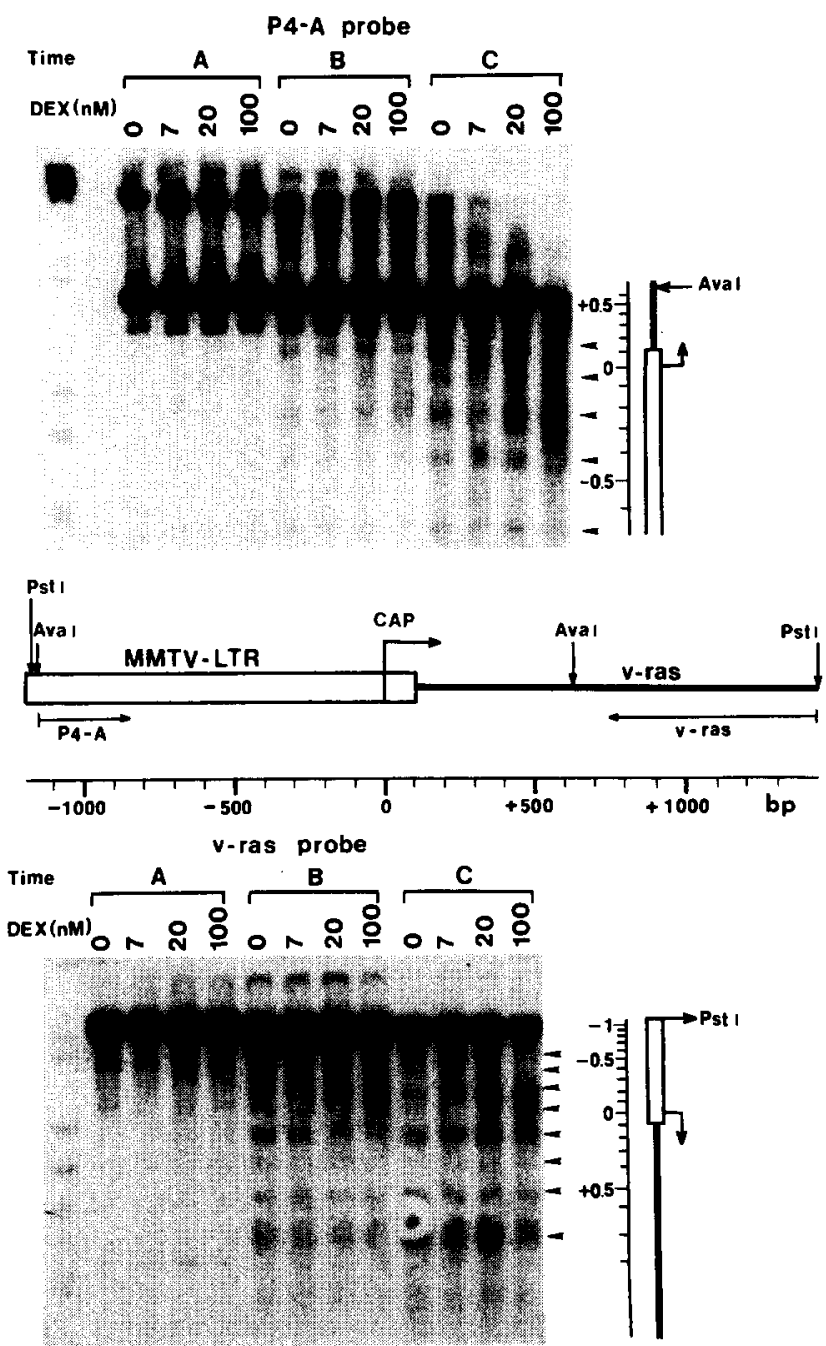

Fig. 2. Nucleosome positioning on MMTV LTR. Nuclei from 1361.5 cells treated with $0,7,20$ and $100 \mathrm{nM}$ dexamethasone were resuspended at an $\mathrm{OD}_{260}=15$ and cleaved with MPE-Fe(II) for various times: A) no MPE-Fe(II), B) $20 \mathrm{~min}$, C) $40 \mathrm{~min}$. After purification, cellular DNAs were cut to completion with AvaI (top panel) or Pst I (bottom panel). The arrows indicate the positions of the cutting sites in the absence of hormone. After electrophoresis on a $2 \%$ agarose gel, the DNAs were transferred onto a membrane and hybridized with the indicated probes. For experimental details see Ref. [11].

receptor is efficiently translocated to the nucleus, is unable to induce the DNasel hypersensitive site and, in the presence of hormone, prevents its hormono-dependent formation [13]. These results suggest that the antagonist-receptor complex is able to interact with the chromatin but unable to induce its conformational change, suggesting a critical role for this change in transcription stimulation. This is illustrated in Fig. 3, which shows the data obtained from the quantitation of DNasel hypersensitivity studies and transcription rates assayed by nuclear runon, in cells treated with various concentrations of dexamethasone in the absence (black circles) or presence (open circles) of dexamethasone mesylate. There is clearly a linear relationship between the intensity of the hormone-induced

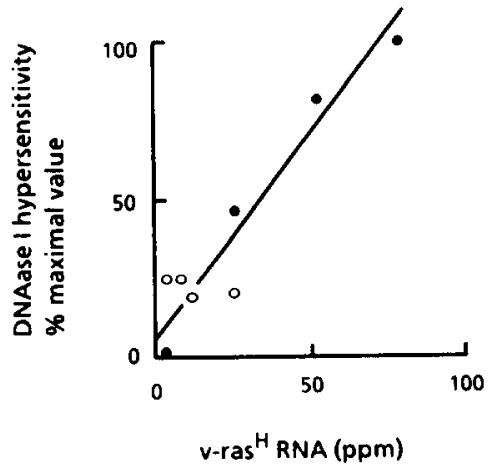

Fig. 3. Correlation between DNasel hypersensitivity and transcriptional activity of the MMTV promoter. 904.13 cells were treated with $0,7,20$ or $100 \mathrm{nM}$ dexamethasone in the presence (open circles) or absence (closed circles) of $1 \mu \mathrm{M}$ dexamethasone mesylate. The values plotted on the graph were calculated from experiments presented in detail in Ref. [13]. 
DNasel hypersensitive site and the transcription rate.

Role of the hormone-receptor complex in maintenance of DNasel hypersensitivity and transcription activation. We have studied the transcription rate of ${ }^{\mathrm{H}} \mathrm{v}$-ras, assayed by nuclear run-on, in 904.13 cells treated with triamcinolone for various times. A maximal transcription rate was reached after $30-40 \mathrm{~min}$ of hormone treatment, and the rate decreased to approx. $30-40 \%$ of the maximal value after $2 \mathrm{~h}$. In cells treated in the same way, nuclear uptake of the hormone-receptor complex paralleled the transcription rate, with a maximum after 30-40 min, followed by a decrease to approx. $50 \%$ of the maximal value after $2 \mathrm{~h}$. This suggests that synthesis of ${ }^{\mathrm{H}} \mathrm{V}$-ras protein causes a change in intracellular receptor distribution. A similar observation has been made upon v-mos protein synthesis [28]. This decrease in nuclear hormone-receptor complex may explain the negative effect on glucocorticoid-regulated gene transcription of an increased expression of several oncogenes, including ${ }^{\mathrm{H}} \mathrm{v}$-ras and $\mathrm{v}-$ mos [29]. We also followed the intensity of the DNasel hypersensitivity site: it increased with the increase of the hormone-receptor complex nuclear uptake but, in contrast, remained constant at its maximal value after at least $2 \mathrm{~h}$ of hormone treatment. These results suggest that (1) the hormone-receptor complex is necessary for the establishment of the DNasel hypersensitive site, but not for its maintenance and (2) the presence of the DNasel hypersensitive site is not sufficient to promote transcriptional activation.

\section{Rat tyrosine aminotransferase promoter}

We have analyzed the chromatin structure of a $1 \mathrm{~Kb}$ region of the rat tyrosine aminotransferase promoter, encompassing the previously described [23-25] hormono-dependent DNasel hypersensitive site. These studies have been performed at a low resolution level, using micrococcal nuclease to probe in vivo nucleosome positioning. In situ cleavage of chromatin from cells untreated with dexamethasone results in a regular cutting pattern with a spacing of $180-220 \mathrm{bp}$, clearly different from the pattern obtained for naked DNA. In the absence of hormone, cutting sites are centered around positions $-3080,-2900,-2700,-2480,-2255$ and -2040 . Treatment of the cells with dexamethasone induces a disruption of the chromatin structure which affects a relatively short stretch of DNA (approx. -2400 to -2650 ) that overlaps two nucleosomes [30].

\section{INTERACTION OF THE CHIMERIC CONSTRUCTS WITH THE NUCLEAR MATRIX}

Active chromatin (containing genes actively transcribed or transcriptionally "poised" chromatin [31]) and inactive chromatin (containing genes that cannot be transcribed) can be fractionated by centrifugation of nuclei digested with micrococcal nuclease and lysed in a lowsalt medium. Active chromatin is associated with the residual pellet (containing the nuclear matrix), while inactive chromatin is recovered in the supernatant. In cell lines containing the chimeric constructs described above, $70 \%$ of the cellular DNA is in the inactive chromatin fraction. In contrast, the chimeras, when probed with labelled ${ }^{\mathrm{H}} \mathrm{V}$-ras $\mathrm{DNA}$, are mostly found in the active chromatin fraction whether or not the cells were treated with the hormone. This suggests an interaction of the constructs with nuclear components, probably the "nuclear matrix". We have investigated the possibility of such an interaction, using in situ and in vitro approaches.

In situ experiments. Nuclei were extracted with LIS (lithium diiodosalycilate) [32], leading to histone-depleted nuclei, digested with a restriction enzyme (Hae III), and the DNA released or associated with the "scaffold" was isolated by centrifugation.

In vitro experiments. Nuclear matrices were prepared [33], incubated with end-labelled DNA fragments from the chimeric construct, and the DNA associated with the nuclear matrix was separated from free DNA by centrifugation.

Results from the two approaches indicate that the DNA sequences located just upstream and downstream of the ${ }^{\mathrm{H}} \mathrm{v}$-ras gene strongly interact with the nuclear matrix. This interaction may play a role in establishing the transcriptional ability of the construct but is probably not directly related to hormonal regulation of the promoter.

\section{DISCUSSION}

The wrapping of eukaryotic DNA on nucleosomes and the formation of higher-order compact structures allows the cell to solve the problem of packaging its DNA. The association of DNA regulatory regions with core histone octamers can be critical, especially if 
nucleosomes are precisely positioned over such sequences. It has been demonstrated that DNA in the nucleosome is bent and kinked and that the DNA helix is distorted (for a review see Ref. [4]). These changes in DNA conformation may affect specific protein-DNA interactions. In addition, the intimate association of core histone octamers with DNA may produce steric hindrances, preventing regulatory factors from binding their targets. Conversely, association of DNA with a chromatin structure containing precisely positioned nucleosomes can play a role in bringing into close vicinity DNA sequences normally at a distance from each other, facilitating protein-protein interactions between DNAbinding regulatory factors. Such a phenomenon has been described for the $h s p 26$ promoter [34].

Precisely positioned nucleosomes have been found, organizing the DNA sequences containing the GREs, on the two steroid-regulated promoters that have been carefully studied: the MMTV LTR and the TAT promoter. In this regard, the MMTV LTR and the glucocorticoid target region of the TAT promoter display similar structural features. A major difference between the two promoters is the different positioning of the GREs as compared to the nucleosomes. In the MMTV LTR, low resolution, in vivo studies, as well as in vitro studies on reconstituted nucleosomes, indicate that the four described GREs are included in a single nucleosome $[11,14,15]$. In the TAT promoter three GREs have been described. In vivo experiments suggest that they probably belong to two different nucleosomes, one of them possibly lying in the linker region between the two nucleosomes. The low level of resolution
( $\pm 20 \mathrm{bp}$ ) of such experiments, however, does not allow us to exclude the localization of two GREs on one nucleosome, with the third GRE in the linker region.

Treatment of cells with dexamethasone, which induces transcription, results in local changes in the chromatin organization of both promoters. These changes affect one nucleosome in MMTV and two nucleosomes in TAT (around position -2500) (Fig. 4).

The exact mechanism leading from steroid receptor interaction with HREs to transcriptional activation remains to be elucidated. Interaction of the hormone-receptor complex with the HRE apparently triggers the process. However, a productive interaction is achieved only when the receptor is complexed with an agonist; interaction with an antagonist-receptor complex is inefficient. Similar conclusions have been drawn from experiments using a recombinant mutated progesterone receptor [35].

The chromatin structural change could result from the release of the histone core or from a change in nucleosome structure, weakening the strength of the interaction between the DNA and the core histone octamer. For the MMTV promoter, binding of glucocorticoid receptor to a nucleosome and NF-I exclusion from a nucleosome prior to receptor binding is strongly suggested by data from both in vitro and in vivo experiments $[12,14,15]$. There is, however, no evidence of a direct action of the glucocorticoid receptor in chromatin rearrangement, and it is not known if the receptor must remain bound to the DNA after NF-I binding in order to maintain MMTV transcription. Using a cell line containing established MMTV constructs [26],

MMTV-LTR

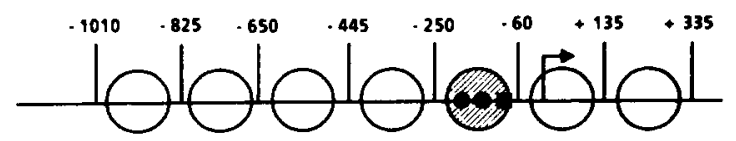

TAT

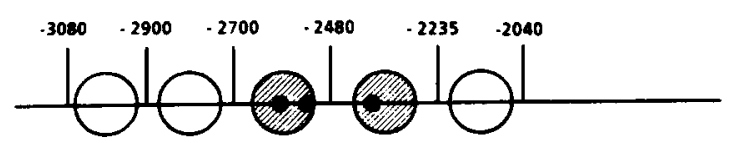

Fig. 4. Nucleosome organization of MMTV and TAT promoters. Vertical bars mark linker regions between nucleosomes, and the numbers on top are the mean cutting site positions. MMTV numbers are from Ref. 11 and TAT numbers from Ref. [30]. Hatched nucleosomes are detected only in the absence of hormone. Small closed circles on the line mark the positions of GREs and the closed box indicates the position of the NF-I binding site. 


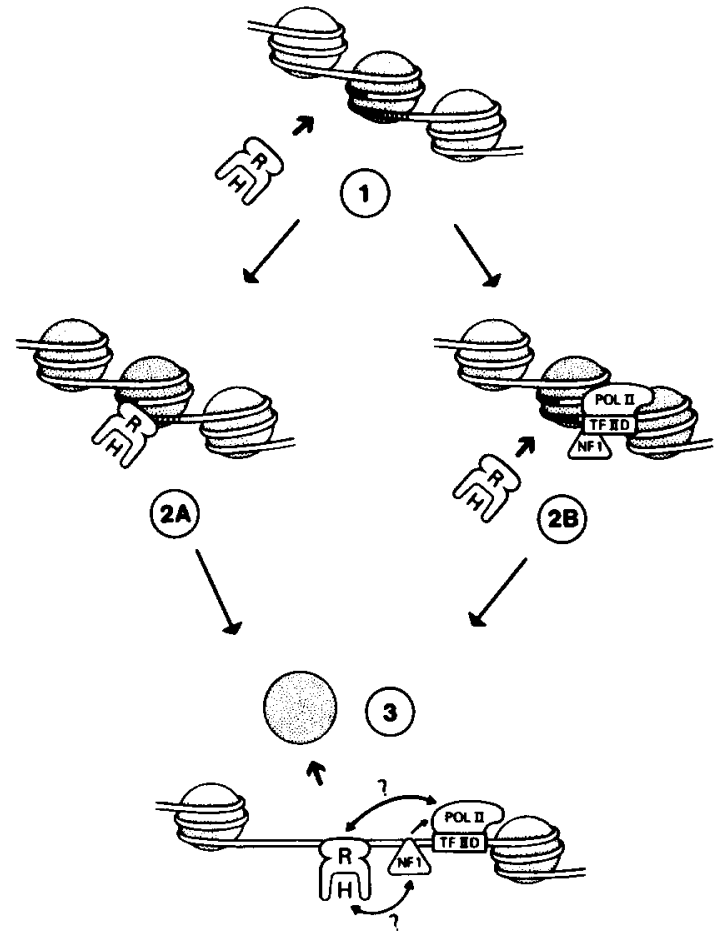

Fig. 5. Mechanism of transcriptional activation of MMTV promoter by glucocorticoids. In the absence of hormone, MMTV LTR DNA is wrapped into precisely positioned nucleosomes. The GREs and the NF-I binding site are within a nucleosome. Transcriptional machinery proteins may (2B) or may not (1) be bound to the promoter in the absence of hormone-receptor complex. In situ studies using Exonuclease III digestion indicate that in the absence of hormone NF-I and TFII-D are not bound to their targets [12]. In vitro studies show that NF-I cannot bind a reconstituted nucleosome [15]. These observations favor a model in which the steps would be (1), (2A), and (3). Current data allow conclusions neither on the extent of nucleosome rearrangement (complete disruption, as presented on the figure, or opening of the core histone octamer) nor on the nature of the process involved. In addition, the following questions remain unanswered: Does the receptor interact directly with the polymerase II complex or is the interaction mediated by other proteins? How does NF-I participate in the transcriptional machinery? Does the receptor remain bound to the DNA during the entire process?

we have observed that depletion of glucocorticoid receptor in nuclei leads to a transcriptionally inactive MMTV promoter, even in a situation in which the NF-I binding site is probably accessible to the factor. These observations suggest that the hormone-receptor complex interaction with the GRE plays a double role in MMTV: change in chromatin structure and direct transactivation of the transcription machinery. Opening of the chromatin structure is probably necessary, but certainly not sufficient, for transcriptional activation. The presence of the hormone-receptor complex as a transactivator interacting with the transcriptional machinery presumably re- mains the critical event for the hormonal response.

For the MMTV promoter, NF-I, which binds in the region whose chromatin structure is disrupted after hormone treatment, has been cited for its importance in hormonal transcriptional activation. In the case of the TAT promoter, the factors binding to the rearranged region remain to be identified and their roles determined. The genomic footprint studies performed in this region have been, up to now, uninformative with regard to this question [36]. Moreover, in contrast with the MMTV LTR, the hormonodependent change in chromatin structure of the TAT promoter takes place at a great distance from the CAP site $(-2500 \mathrm{bp})$. Detailed studies on the chromatin organization of the entire TAT promoter, including all regulatory targets, may be a key to understanding how regulatory signals are transmitted over long distances.

Acknowledgements - We thank Drs G. L. Hager and M. Ostrowski for the gift of cell lines 904.13 and 1361.5. Drs R. Pictet, T. Grange and G. Rigaud kindly provided us with TAT promoter clones. We are particularly grateful to D. Fortin for her excellent technical assistance. The manuscript was prepared with the assistance of J. C. Lambert and C. Legris for the graphics. This work has been supported by the INSERM, CNRS, the Association pour la Recherche sur le Cancer, la section de Paris de la Ligue contre le Cancer, and Roussel Uclaf.

\section{REFERENCES}

1. Scheidereit C., Geisse S., Westphal H. M. and Beato M.: The glucocorticoid receptor binds to defined nucleotide sequences near the promoter of mouse mammary tumor virus. Nature 304 (1983) 749-752.

2. Payvar F., DeFranco D., Firestone G. L., Edgar B., Wrange O., Okret S., Gustafsson J. A. and Yamamoto K. R.: Sequence-specific binding of glucocorticoid receptor to MTV DNA at sites within and upstream of the transcribed region. Cell 35 (1983) 381-392.

3. Pederson D. S., Thoma F. and Simpson R. T.: Core particle, fiber, and transcriptionally active chromatin structure. A. Rev. Cell Biol. 2 (1986) 117-147.

4. Morse R. H. and Simpson R. T.: DNA in the nucleosome. Cell 54 (1988) 285-287.

5. Elgin S. C. R.: The formation and function of DNase I hypersensitive sites in the process of gene activation. J. Biol. Chem. 263 (1988) 19259-19262.

6. Han M., Kim U.-J., Kayne P. and Grunstein M.: Depletion of histone $\mathrm{H} 4$ and nucleosomes activates the PHO5 gene in Saccharomyces cerevisiae. EMBO $\mathrm{Jl} 7$ (1988) 2221-2228.

7. Felsenfeld G., Emerson B. M., Jackson P. D., Lewis C. D. and Nickol J. M.: Chromatin structure near transcriptionally active genes. Prog. Clin. Biol. Res. 218 (1986) 63-74.

8. Svaren J. and Chalkey R.: The structure and assembly of active chromatin. Trends Genetics 6 (1990) 52-56.

9. Hager G. L., Richard-Foy H., Kessel M., Wheeler D., Litchler A. C. and Ostrowski M. C.: The mouse mammary tumor virus model in studies of glucocorticoid regulation. Recent Prog. Horm. Res. 40 (1984) 121-142. 
10. Zaret K. S. and Yamamoto K. R.: Reversible and persistent changes in chromatin structure accompany activation of a glucocorticoid-dependent enhancer element. Cell 38 (1984) 29-38.

11. Richard-Foy H. and Hager G. L.: Sequence specific positioning of nucleosomes over the steroid-inducible MMTV promoter. EMBO Jl 6 (1987) 2321-2328.

12. Cordingley M. G., Riegel A. T. and Hager G. L.: Steroid-dependent interaction of transcription factors with the inducible promoter of mouse mammary tumor virus in vivo. Cell 48 (1987) 261-270.

13. Richard-Foy H., Sistare F. D., Riegel A. T., Simons S. S. and Hager G. L.: Mechanism of dexamethasone 21-mesylate antiglucocorticoid action: II. Receptorantiglucocorticoid complexes do not interact productively with mouse mammary tumor virus long terminal repeat chromatin. Molec. Endocr. 1 (1987) 648-658.

14. Perlman T. and Wrange O.: Specific glucocorticoid receptor binding to DNA reconstituted in a nucleosome. EMBO Jl 7 (1988) 3073-3079.

15. Pina B., Bruggemeier U. and Beato M.: Nucleosome positioning modulates accessibility of regulatory proteins to the mouse mammary tumor virus promoter. Cell 60 (1990) 719-731.

16. Buetti E. and Kuhnel B.: Distinct sequence elements involved in the glucocorticoid regulation of the mouse mammary tumor virus promoter identified by linker scanning mutagenesis. J. Molec. Biol. 190 (1986) 379-389.

17. Morley K. L., Toohey M. G. and Peterson D. O. Transcriptional repression of a hormone-responsive promoter. Nucleic Acids Res. 15 (1987) 6973-6989.

18. Langer S. J. and Ostrowski M. C.: Negative regulation of transcription in vitro by a glucocorticoid response element is mediated by a trans-acting factor. Molec. Cell. Biol. 8 (1988) 3872-3881.

19. Stewart T. A., Hollingshead P. G. and Pitts S. L.: Multiple regulatory domains in the mouse mammary tumor virus long terminal repeat revealed by analysis of fusion genes in transgenic mice. Cell 8 (1988) 473-479.

20. Shinomiya T., Scherer G., Schmid W., Zentgraf $H$. and Schutz G.: Isolation and characterization of the rat tyrosine aminotransferase gene. Proc. Natn. Acad. Sci. U.S.A. 81 (1984) 1346-1350.

21. Grange T., Roux J., Fromont-Racine M. and Pictet R. Positive and negative regulation of a transfected chimeric tyrosine aminotransferase gene: effect of copy number. Exp. Cell Res. 180 (1989) 220-233.

22. Oddos J., Grange T., Carr K. D., Matthews B., Roux J., Richard-Foy $\mathbf{H}$, and Pictet R.: Nucleotide sequence of 10 kilobases of rat tyrosine aminotransferase gene $5^{\prime}$ flanking region. Nucleic Acids Res. 17 (1989) 8877-8878.

23. Jantzen H. M., Strahle U., Gloss B., Stewart F., Schmid W., Boshart M., Miksicek R. and Schutz G.: Cooperativity of glucocorticoid response elements located far upstream of the tyrosine aminotransferase gene. Cell 49 (1987) 29-38.
24. Grange T., Roux J., Rigaud G. and Pictet R.: Two remote glucocorticoid responsive units interact cooperatively to promote glucocorticoid induction of rat tyrosine aminotransferase gene expression. Nucleic Acids Res. 17 (1989) 8695-8709.

25. Nitsch D., Stewart F., Boshart M., Mestril R., Weih F. and Schutz G.: Chromatin structures of the rat tyrosine aminotransferase gene relate to the function of its cis-acting elements. Molec. Cell. Biol. 10 (1990) 3334-3342.

26. Ostrowski M. C., Richard-Foy H., Wolford R. G., Berard D. S. and Hager G. L.: Glucocorticoid regulation of transcription at an amplified episomal promoter. Molec. Cell. Biol. 3 (1983) 2045-2057.

27. Sistare F. D., Hager G. L. and Simons S. S.: Mechanism of dexamethasone 21-mesylate antiglucocorticoid action: I. Receptor-antiglucocorticoid complexes do not competitively inhibit receptor-glucocorticoid complex activation of gene transcription in vivo. Molec. Endocr. 1 (1987) 648-658.

28. Ming Q., Hamilton B. J. and DeFranco D.: v-mos oncoproteins affect the nuclear retention and reutilization of glucocorticoid receptors. Molec. Endocr. 3 (1989) $1279-1288$.

29. Jaggi R., Hock W., Ziemiecki A., Klemenz R., Friis R and Groner B.: Oncogene mediated repression of glucocorticoid hormone response elements and glucocorticoid receptor levels. Cancer Res. 49 (Suppl.) (1989) 2266s-2274s.

30. Carr K. D. and Richard-Foy H.: Glucocorticoids locally disrupt an array of positioned nucleosomes on the rat tyrosine aminotransferase promoter in hepatoma cells. Proc. Natn. Acad. Sci. USA 87, (1990) 9300-9304.

31. Gross D. S. and Garrard W. T.: Nuclease hypersensitive sites in chromatin. A. Rev. Biochem. 57 (1988) 159-197.

32. Mirkovitch J., Mirault M. E. and Laemmli U. K.: Organization of the higher-order chromatin loop: specific DNA attachment sites on nuclear scaffold. Cell 39 (1984) 223-232.

33. Cockerill P. N. and Garrard W. T.: Chromosomal loop anchorage of the kappa immunoglobulin gene occurs next to the enhancer in a region containing topoisomerase II sites. Cell 44 (1986) 273-282.

34. Thomas G. H. and Elgin S. C. R.: Protein/DNA architecture of the DNase I hypersensitive region of the Drosophila hsp 26 promoter. $E M B O \quad J l 7$ (1988) 2191-2201.

35. Guiochon-Mantel A., Loosfelt H., Ragot T., Bailly A., Atger M., Misrahi M., Perricaudet M. and Milgrom E.: Receptors bound to antiprogestin form abortive complexes with hormone responsive elements. Nature 336 (1988) 695-698.

36. Becker P. B., Gloss B., Schmid W., Strahle U, and Schutz G.: In vivo protein-DNA interaction in a glucocorticoid response element require the presence of the hormone. Nature 324 (1986) 686-688. 